\title{
Absence of terminal deoxynucleotidyl transferase expression identifies a subset of high-risk adult T-lymphoblastic leukemia/lymphoma
}

\author{
Yi Zhou ${ }^{1,4}$, Xiangshan Fan ${ }^{1}$, Mark Routbort ${ }^{1}$, C Cameron Yin ${ }^{1}$, Rajesh Singh ${ }^{1}$, \\ Carlos Bueso-Ramos ${ }^{1}$, Deborah A Thomas ${ }^{2}$, Denái R Milton ${ }^{3}$, L Jeffrey Medeiros ${ }^{1}$ \\ and Pei Lin ${ }^{1}$ \\ ${ }^{1}$ Department of Hematopathology, University of Texas MD Anderson Cancer Center, Houston, TX, USA; \\ ${ }^{2}$ Department of Leukemia, University of Texas MD Anderson Cancer Center, Houston, TX, USA and \\ ${ }^{3}$ Department of Biostatics, University of Texas MD Anderson Cancer Center, Houston, TX, USA
}

\begin{abstract}
Terminal deoxynucleotidyl transferase (TdT) can be downregulated in minimal residual disease of T-acute lymphoblastic leukemia/lymphoma (T-ALL/LBL) after chemotherapy. TdT-negative T-ALL/LBL cases are rare and have not been well characterized. We studied the clinicopathologic features of de novo T-ALL/LBL patients treated at our institution during 2003-2011, with an emphasis on immunophenotype and survival of TdTnegative versus TdT-positive cases. Absence of TdT expression was defined as $<10 \%$ lymphoblasts positive. Seven (12\%) TdT-negative cases were identified from a cohort of 59 de novo T-ALL/LBL. The TdT-negative and TdT-positive cases were similar with regard to gender, percentage of patients with a high leukocyte count $(>100 \times 10 \%)$, central nervous system involvement, and an abnormal karyotype. However, patients with TdT-negative T-ALL/LBL had a significantly higher rate of disease progression and shorter overall survival. Although not statistically significant, TdT-negative T-ALL/LBL cases were associated with an older median age and higher percentage of 'early T precursor' (ETP) immunophenotype than TdT-positive cases. Absence of TdT expression identifies a subset of high-risk T-ALL/LBL that overlaps with, but is not identical to, the ETP leukemia, providing additional prognostic value.

Modern Pathology (2013) 26, 1338-1345; doi:10.1038/modpathol.2013.78; published online 24 May 2013
\end{abstract}

Keywords: early T precursor; immunophenotype; prognosis; T-acute lymphoblastic leukemia/lymphoma; TdT

T-acute lymphoblastic leukemia/lymphoma (T-ALL/ LBL) is an aggressive neoplasm derived from T-cell progenitors that represents $\sim 15$ and $25 \%$ of all ALL/LBL cases in children and adults, respectively. The disease can initially present as lymphoblastic lymphoma (T-LBL) involving thymus, nodal, and extranodal sites, and/or as acute lymphoblastic leukemia (T-ALL) involving primarily peripheral blood and bone marrow. The outcome of patients

Correspondence: Dr P Lin, MD, Department of Hematopathology, Box 72, MD Anderson Cancer Center, 1515 Holcombe Boulevard, Houston, TX 77030, USA.

E-mail: peilin@mdanderson.org

${ }^{4}$ Current address: Department of Laboratory Medicine and Pathology, University of Minnesota Medical School, Mayo Mail Code 609, 420 Delaware Street S.E., Minneapolis, MN 55455, USA.

Received 20 August 2012; revised 7 January 2013; accepted 8 January 2013; published online 24 May 2013 with T-ALL/LBL has been significantly improved with intensified chemotherapy. Complete remission can be achieved initially in over $90 \%$ of T-ALL/LBL patients, but a substantial subset of patients eventually develop relapsed disease. The 5-year overall survival for patients with T-ALL/LBL is over $80 \%$ in children ${ }^{1}$ and $\sim 50 \%$ in adults, ${ }^{2-5}$ with most relapses occurring within 2 years after initial remission. ${ }^{4}$ Patients with relapsed T-ALL/LBL usually respond poorly to augmented salvage chemotherapy and allogeneic hematopoietic stem cell transplant. ${ }^{4,6}$ The key to improve survival therefore is to identify patients at high risk for relapse at the time of initial diagnosis and to implement risk-adapted therapy.

Immunophenotyping is essential in the diagnostic workup of T-ALL/LBL. Lymphoblasts express cytoplasmic CD3 and other T-lineage makers as well as one or more markers of immaturity, including CD34, 
CD1a, and terminal deoxynucleotidyl transferase (TdT). The latter is normally expressed in T- (and B-) cell precursors and is a marker expressed in 95\% of cases of ALL/LBL by flow cytometry. 7,8 TdTnegative T-ALL/LBL has not been reported in a large study, but occasional case reports of TdT-negative T-ALL/LBL can be found in the literature. ${ }^{9-12}$ In patients who had T-ALL/LBL without TdT expression, response to vincristine and prednisone therapy was poor. ${ }^{9,10}$ A recent study has shown that TdT expression in T-ALL/LBL can be gradually downregulated in up to $90 \%$ of cases of T-ALL/LBL following induction chemotherapy, at the time of detection of minimal residual disease (MRD). ${ }^{13}$ This finding suggests that therapy modulates TdT expression, either by promoting maturation of neoplastic cells or by selecting preexistent TdTnegative cells. As MRD at the end of induction is one of the most significant risk factors for predicting relapse and adverse outcome in patients with T-ALL/LBL, ${ }^{14-17}$ diminished or absent TdT expression may be a marker of chemoresistance. This finding, along with the few case reports of TdT-negative T-ALL/LBL with poor prognosis, therefore prompted us to query if negative/low $\mathrm{TdT}$ in T-ALL/LBL is associated with an adverse outcome to frontline chemotherapy.

Two recent studies have shown that a subset of T-ALL/LBL cases with an immunophenotype considered to be of an early T-precursor origin, 'early T precursor' (ETP), belongs to a very high risk group. The ETP immunophenotype is described as lack of CD1a and CD8, CD5-/dim +, and expression of one or more myeloid or stem cell-related antigens. ${ }^{18,19}$ Both studies focused on pediatric patients and did not further specify whether TdTnegative T-ALL/LBL cases fall into the ETP type of T-ALL/LBL.

In this single institution study of de novo T-ALL/ LBL, we identified a group of patients with TdTnegative T-ALL/LBL and compared their clinical presentation, immunophenotype, karyotype, and outcome to a group of patients with TdT-positive T-ALL/LBL. We also explored the potential overlap between TdT-negative T-ALL/LBL and T-ALL/LBL cases with an ETP immunophenotype.

\section{Materials and methods}

\section{Study Group}

We reviewed available data on de novo T-ALL/LBL patients who were diagnosed and treated at our hospital between 2003 and 2011. All T-ALL/LBL cases expressed cytoplasmic CD3 (cCD3) and completely lacked myeloperoxidase (MPO) activity assessed by cytochemical analysis on peripheral blood or bone marrow smears. Cases of mixed T-/myeloid acute leukemia were excluded. The distinction between T-ALL and T-LBL was made based on clinical and pathology findings. T-ALL was defined as presenting primarily as leukemia, with or without concurrent extramedullary involvement, whereas T-LBL was defined primarily as an extramedullary disease with $<25 \%$ lymphoblasts in blood or bone marrow. All patients in the study group were treated with frontline chemotherapy including hyperfractionated cyclophosphamide, vincristine, daunorubicin (Adriamycin), and dexamethasone (modified hyper-CVAD), or augmented Berlin-Frankfurt-Munster therapy for younger patients, with or without nelarabine and central nervous system (CNS) prophylaxis. Patients with mediastinal disease at presentation received radiation therapy for consolidation. Patients who developed relapsed disease were treated with various augmented salvage chemotherapy regimens, and allogeneic stem cell transplant in a subset. T-ALL/ LBL patients with relapsed disease referred to our hospital for salvage treatment were excluded. This study was approved by the MDACC institutional review board; written informed consents were obtained in accordance with the Declaration of Helsinki Principles.

\section{Flow Cytometry Immunophenotyping}

As part of the routine diagnostic workup, multicolor flow cytometric immunophenotypic analysis was performed on cell suspensions of fresh tissue and/or bone marrow aspirate samples collected in EDTA. After incubation of cells with monoclonal antibodies for $10 \mathrm{~min}$ at $4{ }^{\circ} \mathrm{C}$, erythrocytes were lysed with $\mathrm{NH}_{4} \mathrm{Cl}$ for $10 \mathrm{~min}$, followed by two washing steps using phosphate-buffered saline solution. The cells were resuspended and fixed with $1 \%$ paraformaldehyde. A panel of markers, including CD1a, CD2, CD3, cytoplasmic CD3, CD4, CD5, CD7, CD8, CD10, CD13, CD33, CD34, CD45, CD56, CD117, MPO, TdT, and HLA-DR, were used. All antibodies were obtained from BD Biosciences (San Jose, CA, USA), except anti-CD10 obtained from Beckman Coulter (Brea, CA, USA) and anti-TdT was obtained from Supertechs (Rockville, MD, USA). The analyses were performed using FACScan, FACSCaliber, or FACSCanto flow cytometers (BD).

\section{TdT Immunoreactivity}

TdT immunoreactivity was determined by flow cytometry immunophenotyping (FCI) of fresh tissue biopsy specimens or bone marrow aspirate specimens and/or by immunohistochemical (IHC) analysis of formalin-fixed and paraffin-embedded tissue sections. For FCI analysis, TdT immunoreactivity was determined by comparing TdT-specific monoclonal antibody (FITC, Cat\# 6100, Supertechs) to its isotype control and internal negative control. For IHC staining, rabbit anti-TdT polyclonal antibody (1:20, DAKO, Denmark) was used on biopsy 
sections. TdT-negative cases were defined as TdT expression in $<10 \%$ of $\mathrm{T}$ lymphoblasts by IHC and FCI studies, as previously recommended. ${ }^{20}$ All TdTnegative cases identified by FCI were confirmed by IHC staining.

\section{Statistical Analysis}

Descriptive statistics were presented for demographic and clinical characteristics. Categorical measures were summarized using frequencies and percentages and assessed using Fisher's exact tests. Continuous measures were summarized using medians and ranges and assessed using Kruskal-Wallis tests. Progression of disease and overall survival were estimated using Kaplan-Meier survival curves and the log-rank test was used to assess differences between the groups. A multivariate Cox proportional hazards regression model was fit to determine the association between progression of disease and age, gender, initial disease site, white blood cell (WBC) count, CNS involvement, ETP immunophe- notype status, and TdT status. A similar model was fit for overall survival. All statistical tests used a significance level of $5 \%$. All statistical analyses were performed using SAS 9.3 for Windows (Copyright 2011 by SAS Institute, Cary, NC, USA).

\section{Results}

The study included 59 patients with de novo T-ALL/ LBL from 2003 to 2011. There were 41 males (69\%) and 18 females (31\%) with a median age of 31 years (range, 2-77 years). In all, 22 (37\%) patients presented initially with only leukemia, 20 (34\%) patients presented with leukemia but also had extramedullary involvement, and $17(29 \%)$ patients presented primarily with T-LBL. Together, 37 $(63 \%)$ patients demonstrated extramedullary disease. The median WBC count among patients who presented with leukemia was $12.1 \times 10^{9} / 1$ (range $\left.0.4-241 \times 10^{9} / 1\right)$. Twelve $(20 \%)$ patients presented with a WBC count $>100 \times 10^{9} / 1$ and $10(19 \%)$
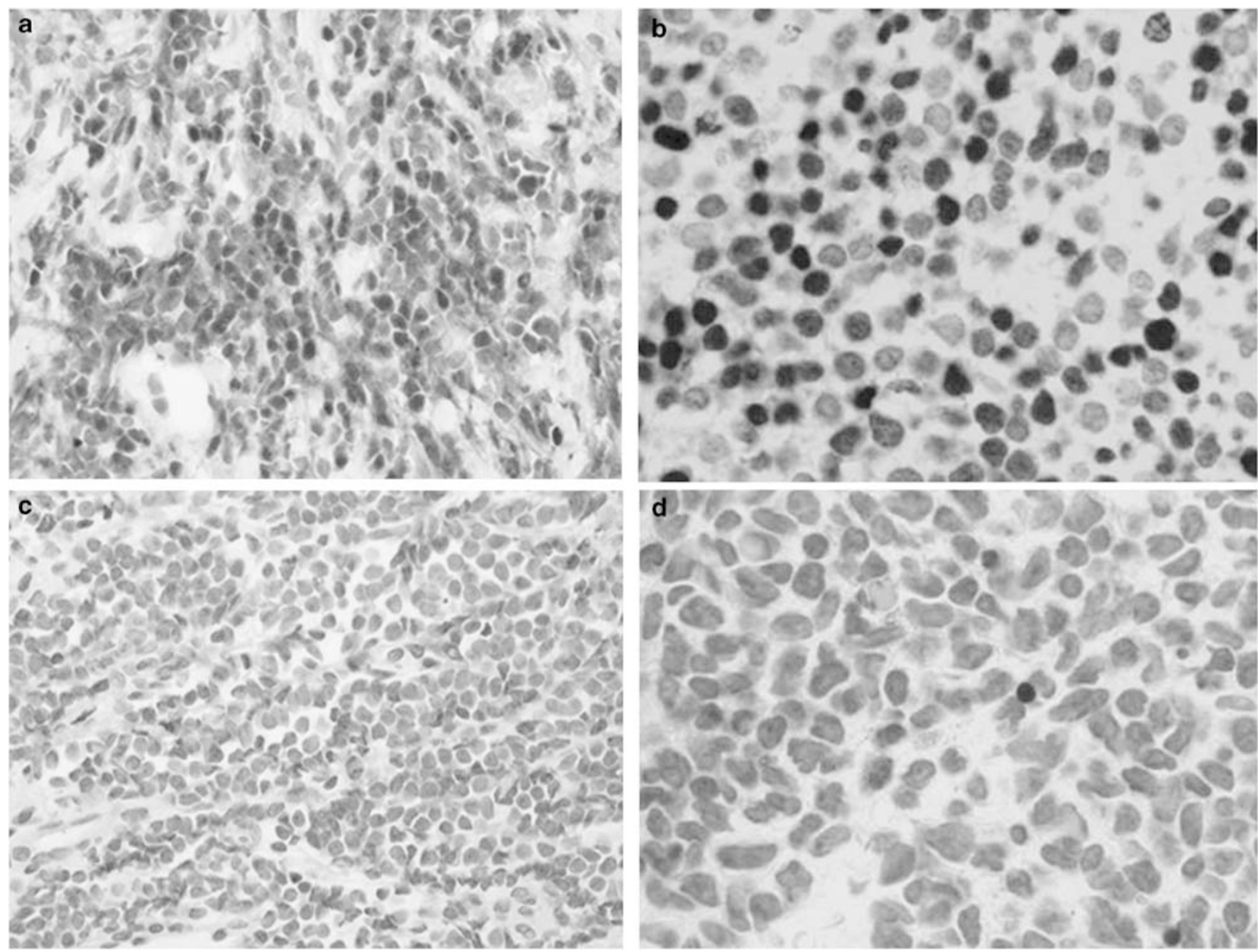

Figure 1 TdT immunohistochemical stains, $\times$ 400. (a) TdT-positive T-lymphoblastic lymphoma and (b) T-acute lymphoblastic leukemia in bone marrow. (c) TdT-negative T-lymphoblastic lymphoma and (d) T-acute lymphoblastic leukemia in bone marrow. 
Table 1 Comparison of patient demographics and clinical characteristics by TdT status and ETP status

\begin{tabular}{|c|c|c|c|c|c|c|c|}
\hline Parameter & $\begin{array}{l}\text { All patients } \\
(\mathrm{N}=59)\end{array}$ & $\begin{array}{l}T d T+ \\
(\mathrm{N}=52)\end{array}$ & $\begin{array}{l}T d T- \\
(\mathrm{N}=7)\end{array}$ & P-value & $\begin{array}{l}\text { ETP, no } \\
(\mathrm{N}=48)\end{array}$ & $\begin{array}{c}\text { ETP, yes } \\
(\mathrm{N}=9)\end{array}$ & $\mathrm{P}$-value $\mathrm{a}^{\mathrm{a}}$ \\
\hline Age (years) & & & & $0.27^{\mathrm{b}}$ & & & $0.56^{\mathrm{b}}$ \\
\hline Median & 31 & 31 & 47 & & 31 & 36 & \\
\hline Range & $2-77$ & $2-77$ & $13-76$ & & $2-77$ & $19-66$ & \\
\hline Age (years), n (\%) & & & & 0.19 & & & 0.58 \\
\hline$>18$ & $52(88.1)$ & $47(90.4)$ & $5(71.4)$ & & $41(85.4)$ & $9(100)$ & \\
\hline$\leq 18$ & $7(11.9)$ & $5(9.6)$ & $2(28.6)$ & & $7(14.6)$ & $0(0)$ & \\
\hline Gender, n (\%) & & & & 0.66 & & & 1.00 \\
\hline Male & $41(69.5)$ & $37(71.2)$ & $4(57.1)$ & & $34(70.8)$ & 6 (66.7) & \\
\hline Female & $18(30.5)$ & $15(28.8)$ & $3(42.9)$ & & $14(29.2)$ & $3(33.3)$ & \\
\hline Initial disease site, $\mathrm{n}(\%)$ & & & & 0.70 & & & 0.07 \\
\hline Extramedullary & $37(62.7)$ & $32(61.5)$ & $5(71.4)$ & & $32(66.7)$ & $3(33.3)$ & \\
\hline Leukemia & $22(37.3)$ & $20(38.5)$ & $2(28.6)$ & & $16(33.3)$ & $6(66.7)$ & \\
\hline$W B C, \mathrm{n}(\%)$ & & & & 0.62 & & & 1.00 \\
\hline$>100 \mathrm{~K} / \mu \mathrm{l}$ & $12(20.3)$ & $10(19.2)$ & $2(28.6)$ & & $10(20.8)$ & $2(22.2)$ & \\
\hline$<100 \mathrm{~K} / \mu \mathrm{l}$ & $47(79.7)$ & $42(80.8)$ & $5(71.4)$ & & $38(79.2)$ & $7(77.8)$ & \\
\hline$C N S, \mathrm{n}(\%)$ & & & & 1.00 & & & 1.00 \\
\hline Positive & $11(18.6)$ & $10(19.2)$ & $1(14.3)$ & & $9(18.8)$ & $2(22.2)$ & \\
\hline Negative & $48(81.4)$ & $42(80.8)$ & $6(85.7)$ & & $39(81.3)$ & $7(77.8)$ & \\
\hline ETP, n (\%) & & & & 0.07 & & & \\
\hline Yes & $9(15.8)$ & $6(12.0)$ & $3(42.9)$ & & & & \\
\hline No & $48(84.2)$ & $44(88.0)$ & $4(57.1)$ & & & & \\
\hline Unknown & & 2 & 0 & & & & \\
\hline$T d T, \mathrm{n}(\%)$ & & & & & & & 0.07 \\
\hline Negative & 7 (11.9) & & & & $4(8.3)$ & $3(33.3)$ & \\
\hline Positive & $52(88.1)$ & & & & $44(91.7)$ & $6(66.7)$ & \\
\hline Karyotype, n (\%) & & & & 1.00 & & & 0.19 \\
\hline Abnormal & $22(51.2)$ & $19(50.0)$ & $3(60.0)$ & & $17(45.9)$ & $5(83.3)$ & \\
\hline Diploid & $21(48.8)$ & $19(50.0)$ & $2(40.0)$ & & $20(54.1)$ & 1 (16.7) & \\
\hline Unknown & 16 & 14 & 2 & & 11 & 3 & \\
\hline
\end{tabular}

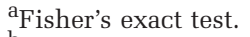

bruskal-Wallis test.

patients had CNS involvement at the time of initial diagnosis.

\section{TdT-Negative T-ALL/LBL}

TdT expression was assessed by flow cytometry and/or IHC. The level of TdT expression varied among different cases and within each tumor. Of the 59 cases, $7(12 \%)$ cases displayed nearly uniform absence of TdT expression, confirmed by IHC staining (Figure 1). There were 4 males and 3 females with a median age of 47 years (range, 13-76 years). Two patients presented with a WBC count $>100 \times 10^{9} / 1$ and one patient had CNS involvement at the time of initial diagnosis. Three of five cases $(60 \%)$ analyzed successfully by conventional cytogenetics had an abnormal karyotype. There were no significant differences with regard to gender, site of involvement, frequency of a high leukocyte count ( $\left.>100 \times 10^{9} / 1\right)$, and an abnormal karyotype between patients with TdT-negative versus TdT-positive T-ALL/LBL. The median age for the TdT-negative cases was higher compared with the positive cases, but this difference was not statistically significant (Table 1).

\section{T-ALL/LBL with an ETP Immunophenotype}

Nine (16\%) of 57 analyzed cases with sufficient immunophenotypic data for assessment had an ETP immunophenotype. These cases were uniformly negative for CD1a and CD8 and uniformly positive for cCD3 and CD7; CD5 was partially positive in $<50 \%$ of neoplastic cells in all cases; other markers were variably positive, including CD2 (3 of 9 cases, 33\%), sCD3 ( 1 of 9 cases, 11\%), CD10 (1 of 8 cases, 12\%), CD34 (6 of 9 cases, 67\%), CD117 (2 of 7 cases, 29\%), CD13 (2 of 6 cases, 33\%), CD33 (6 of 7 cases, $86 \%$ ), HLA-DR (3 of 9 cases, 33\%), and TdT (6 of 9 cases, 67\%). There were 6 males and 3 females with a median age of 36 years (range, 19-66 years). Two $(22 \%)$ patients presented with WBC count $>100 \times 10^{9} / \mathrm{l}$ and two patients had CNS involvement at initial diagnosis. Cytogenetic analysis showed an abnormal karyotype in 5 (83\%) of 6 cases. There were no significant differences in age, gender, site, initial WBC count, and abnormal karyotype between cases with or without an ETP phenotype (Table 1). The TdTnegative cases ( 3 of $7 ; 43 \%$ ) were more likely to have an ETP phenotype than TdT-positive cases (6 of 50; $12 \% ; P=0.07$ ), but this difference was not statistically significant (Table 1). 
Table 2 Progression of disease

\begin{tabular}{|c|c|c|c|c|c|}
\hline Parameter & Total & Disease progressed, n (\%) & 3-Year progression, $\%$ & $\mathrm{P}$-value ${ }^{\mathrm{a}}$ & $\mathrm{P}$-value $\mathrm{b}^{\mathrm{b}}$ (multivariate) \\
\hline All patients & 59 & $22(37.3)$ & 39 & & \\
\hline $\begin{array}{l}\text { Age (years) } \\
\quad>35 \\
\leq 35\end{array}$ & $\begin{array}{l}24 \\
35\end{array}$ & $\begin{array}{r}9(37.5) \\
13(37.1)\end{array}$ & $\begin{array}{l}39 \\
39\end{array}$ & 0.81 & 0.50 \\
\hline $\begin{array}{l}\text { Gender } \\
\text { Male } \\
\text { Female }\end{array}$ & $\begin{array}{l}41 \\
18\end{array}$ & $\begin{array}{r}17(41.5) \\
5(27.8)\end{array}$ & $\begin{array}{l}43 \\
31\end{array}$ & 0.31 & 0.43 \\
\hline $\begin{array}{l}\text { Initial disease site } \\
\text { Extramedullary } \\
\text { Leukemia }\end{array}$ & $\begin{array}{l}37 \\
22\end{array}$ & $\begin{array}{l}10(27.0) \\
12(54.5)\end{array}$ & $\begin{array}{l}32 \\
50\end{array}$ & 0.07 & 0.40 \\
\hline $\begin{array}{l}W B C \\
\qquad>100 \mathrm{~K} / \mu \mathrm{l} \\
\quad<100 \mathrm{~K} / \mu \mathrm{l}\end{array}$ & $\begin{array}{l}12 \\
47\end{array}$ & $\begin{array}{l}11(91.7) \\
11(23.4)\end{array}$ & $\begin{array}{l}92 \\
23\end{array}$ & $<0.0001$ & 0.006 \\
\hline $\begin{array}{l}\text { CNS } \\
\text { Positive } \\
\text { Negative }\end{array}$ & $\begin{array}{l}11 \\
48\end{array}$ & $\begin{array}{r}8(72.7) \\
14(29.2)\end{array}$ & $\begin{array}{l}76 \\
30\end{array}$ & 0.003 & 0.21 \\
\hline $\begin{array}{l}\text { ETP } \\
\text { Yes } \\
\text { No } \\
\text { Unknown }\end{array}$ & $\begin{array}{r}9 \\
48 \\
2\end{array}$ & $\begin{array}{r}7(77.8) \\
15(31.3)\end{array}$ & $\begin{array}{l}87 \\
32\end{array}$ & 0.0002 & 0.30 \\
\hline $\begin{array}{l}T d T \\
\text { Negative } \\
\text { Positive }\end{array}$ & $\begin{array}{r}7 \\
52\end{array}$ & $\begin{array}{r}6(85.7) \\
16(30.8)\end{array}$ & $\begin{array}{l}86 \\
32\end{array}$ & $<0.0001$ & 0.0001 \\
\hline $\begin{array}{l}\text { Karyotype } \\
\text { Abnormal } \\
\text { Diploid } \\
\text { Unknown }\end{array}$ & $\begin{array}{l}22 \\
21 \\
16\end{array}$ & $\begin{array}{r}12(54.5) \\
7(33.3)\end{array}$ & $\begin{array}{l}60 \\
31\end{array}$ & 0.09 & \\
\hline
\end{tabular}

${ }^{\mathrm{a}}$ Log-rank test.

${ }^{\mathrm{b}}$ Wald $\chi^{2}$ test (Cox proportional hazards model).

\section{Disease Progression, Survival, and Risk Factor Analysis}

Of the 59 patients, 56 (95\%) achieved complete remission after induction, defined as lymphoblasts $<5 \%$ in peripheral blood and bone marrow aspirate smears and/or nonavid FDG PET/CT scan. Seven patients had incomplete blood count recovery. Induction failed in three patients: two had an ETP phenotype (one of them was TdT negative) and one was positive for CD1a and TdT. With a median follow-up of 32 months (range, 6-94 months) for patients who achieved complete remission, 19 (34\%) patients relapsed with a median time to progression of 8.3 months (range, 1.4-41 months). Absence of TdT expression was maintained in each of the $\mathrm{TdT}$ negative cases at the time of relapse. Twenty (34\%) patients died after disease progression, including induction failure and relapse. Six patients received allogeneic stem cell transplant after relapse and one $(17 \%)$ of them remains alive. Univariate analysis found that WBC $>100 \times 10^{9} / \mathrm{l}$, CNS involvement, ETP phenotype, and absence of TdT were significant risk factors for disease progression (Table 2) and a shorter overall survival (Table 3; Figure 2). The 3-year cumulative frequency of progression was $39 \%$ in the study cohort, but $92 \%$ in patients with WBC $>100 \times 10^{9} / 1, \quad 76 \%$ in patients with CNS involvement, $87 \%$ in cases with an ETP phenotype, or $86 \%$ in negative TdT cases. The 3-year overall survival was $61 \%$ in the study cohort, but $19 \%$ in patients with WBC $>100 \times 10^{9} / 1,28 \%$ in patients with CNS involvement, $13 \%$ in cases with an ETP phenotype and $0 \%$ in negative $\mathrm{TdT}$ cases. In a multivariate analysis that included age, WBC $>100 \times 10^{9} / 1$, CNS involvement, ETP phenotype, and absence of TdT, negative TdT remained a significant independent risk factor predicting disease progression $(P=0.0001$; Table 2$)$ and shorter overall survival (Table 3).

We further analyzed the clinical outcome of the seven pediatric patients aged $\leq 18$ years. Among them, 2 had TdT-negative T-ALL/LBL, and none had an ETP phenotype. Of the 7 patients, 2 relapsed: one was a 2-year-old patient with TdT-positive T-ALL and the other a 15-year-old patient with TdT-negative T-ALL/ LBL. Thus, in this limited pediatric group, 1 of $2(50 \%)$ patients with TdT-negative T-ALL relapsed, as compared with 1 out of $5(20 \%)$ patients with TdT-positive T-ALL/LBL. In comparison, 5 of 52 adult patients had TdT-negative T-ALL/LBL; all 5 (100\%) patients relapsed within 12 months of achieving remission.

\section{Discussion}

In this study, the most notable difference between TdT-negative and TdT-positive T-ALL/LBL was the 
Table 3 Overall survival

\begin{tabular}{|c|c|c|c|c|c|}
\hline Parameter & Total & Dead, n (\%) & 3-Year overall survival, \% & $\mathrm{P}$-value $\mathrm{a}^{\mathrm{a}}$ & $\mathrm{P}$-value ${ }^{\mathrm{b}}$ (multivariate) \\
\hline All patients & 59 & $20(33.9)$ & 61 & & \\
\hline $\begin{array}{l}\text { Age (years) } \\
\quad>35 \\
\quad \leq 35\end{array}$ & $\begin{array}{l}24 \\
35\end{array}$ & $\begin{array}{r}8(33.3) \\
12(34.3)\end{array}$ & $\begin{array}{l}64 \\
60\end{array}$ & 0.802 & 0.69 \\
\hline $\begin{array}{l}\text { Gender } \\
\text { Male } \\
\text { Female }\end{array}$ & $\begin{array}{l}41 \\
18\end{array}$ & $\begin{array}{r}15(36.6) \\
5(27.8)\end{array}$ & $\begin{array}{l}57 \\
69\end{array}$ & 0.475 & 0.95 \\
\hline $\begin{array}{l}\text { Initial disease site } \\
\text { Extramedullary } \\
\text { Leukemia }\end{array}$ & $\begin{array}{l}37 \\
22\end{array}$ & $\begin{array}{r}9(24.3) \\
11(50.0)\end{array}$ & $\begin{array}{l}72 \\
48\end{array}$ & 0.159 & 0.68 \\
\hline $\begin{array}{l}W B C \\
\quad>100 \\
\quad<100\end{array}$ & $\begin{array}{l}12 \\
47\end{array}$ & $\begin{array}{l}10(83.3) \\
10(21.3)\end{array}$ & $\begin{array}{l}19 \\
75\end{array}$ & $<0.0001$ & 0.03 \\
\hline $\begin{array}{l}\text { CNS } \\
\text { Positive } \\
\text { Negative }\end{array}$ & $\begin{array}{l}11 \\
48\end{array}$ & $\begin{array}{r}8(72.7) \\
12(25.0)\end{array}$ & $\begin{array}{l}28 \\
70\end{array}$ & 0.003 & 0.09 \\
\hline $\begin{array}{l}\text { ETP } \\
\text { Yes } \\
\text { No } \\
\text { Missing }\end{array}$ & $\begin{array}{r}9 \\
48 \\
2\end{array}$ & $\begin{array}{r}7(77.8) \\
13(27.1)\end{array}$ & $\begin{array}{l}13 \\
68\end{array}$ & $<0.0001$ & 0.01 \\
\hline $\begin{array}{l}T d T \\
\quad \text { Negative } \\
\text { Positive }\end{array}$ & $\begin{array}{r}7 \\
52\end{array}$ & $\begin{array}{r}5(71.4) \\
15(28.8)\end{array}$ & $\begin{array}{r}0 \\
67\end{array}$ & $<0.0001$ & 0.0003 \\
\hline $\begin{array}{l}\text { Karyotype } \\
\text { Abnormal } \\
\text { Diploid } \\
\text { Missing }\end{array}$ & $\begin{array}{l}22 \\
21 \\
16\end{array}$ & $\begin{array}{r}11(50.0) \\
6(28.6)\end{array}$ & $\begin{array}{l}40 \\
71\end{array}$ & 0.067 & \\
\hline
\end{tabular}

${ }^{\mathrm{a}}$ Log-rank test.

${ }^{\mathrm{b}}$ Wald $\chi^{2}$ test (Cox proportional hazards model).
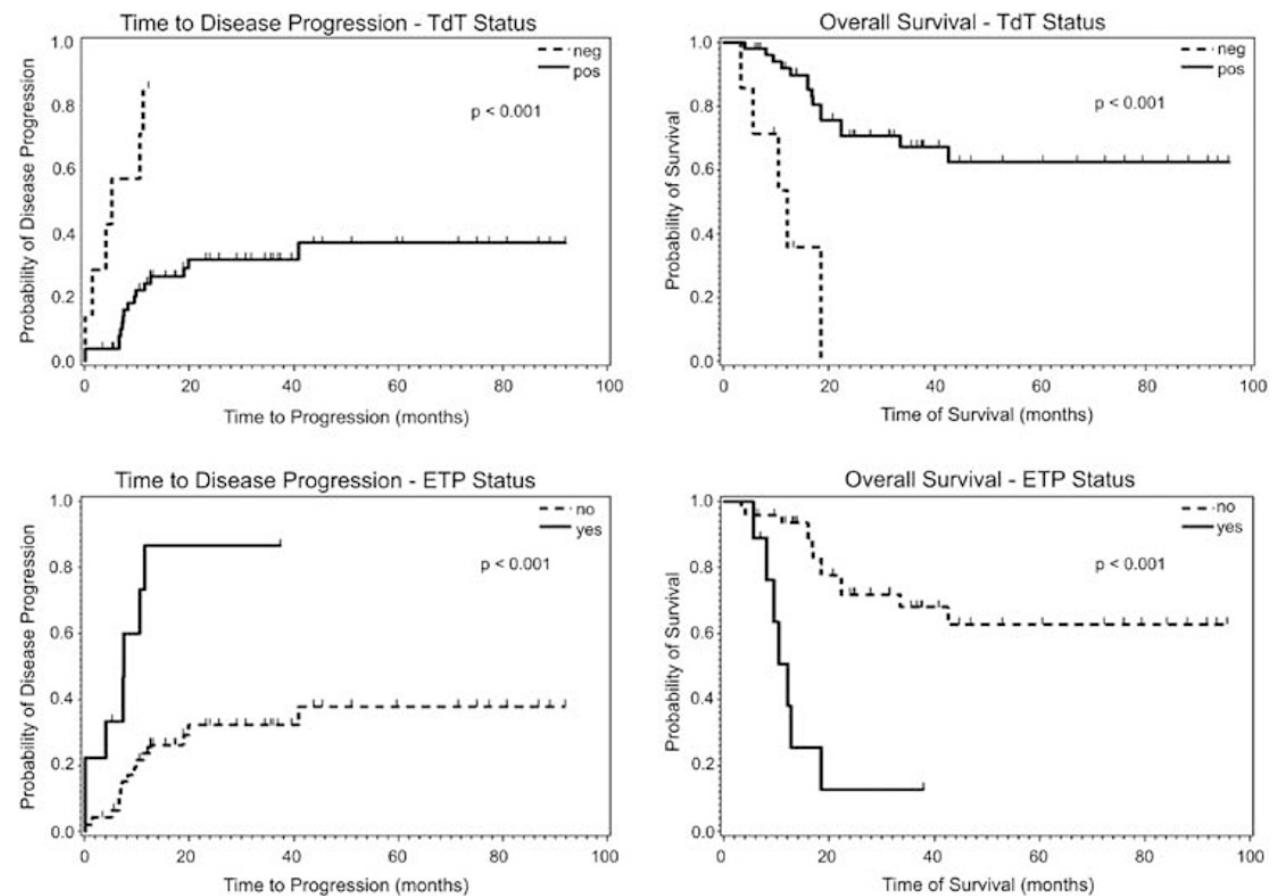

Figure 2 Comparison of time to progression and overall survival between patients with TdT-positive versus TdT-negative T-ALL/LBL (a, b); and patients with T-ALL/LBL with or without an early T-precursor (ETP) phenotype (c, d). 
poorer outcome, association with an ETP immunophenotype, and more advanced age seen in the TdTnegative subgroup. The frequency of TdT-negative cases in this study, 7 of $59(12 \%)$, is comparable with $10 \%$ reported previously. $8,13,21,22$

The patients in this study were treated either with augmented Berlin-Frankfurt-Munster regimen for younger patients or hyper-CVAD \pm nelarabine regimen for older patients. Overall, 27 of 59 (46\%) patients had one or more risk factors of poor prognosis: $20 \%$ had a WBC count $>100 \times 10^{9} / 1$, $19 \%$ had CNS involvement, $16 \%$ had a neoplasm with an ETP immunophenotype, and 12\% had TdT-negative T-ALL/LBL. Each of these features was significantly associated with a higher risk of relapse and shorter overall survival, but the highest risk was associated with an ETP and TdT-negative immunophenotype.

Part of the high risk observed in TdT-negative ALL/LBL can be attributable to ETP. TdT-negative T-ALL/LBL cases were more likely to have an ETP immunophenotype than TdT-positive cases, 43 versus $12 \%$, respectively, although not statistically significant in this small cohort $(P=0.07)$. Early studies have shown that patients with T-ALL/LBL showing a prethymic T-cell immunophenotype, that is, cytoplasmic CD3 + , CD7 + , surface CD3 - , CD1a - , CD 4 - , and CD8 - , have a significantly shorter overall survival than other subgroups. ${ }^{23,24}$ The concept of an ETP immunophenotype has been recently validated and refined by gene expression profiling. ${ }^{19}$ The ETP immunophenotype is characterized by lack of CD1a and CD8 expression, negative or weak CD5 expression, and expression of one or more myeloid or stem cell markers, including CD117, CD34, HLA-DR, CD13, CD33, CD11b, and/or CD65. ETP-positive cases represent $\sim 5-13 \%$ of T-ALL/LBL in pediatric patients and are a very high risk group. ${ }^{19}$ Our study showed in adult patients that $16 \%$ of de novo cases had an ETP immunophenotype and these patients were at significantly higher risk. However, ETP immunophenotype did not account for all cases of TdTnegative T-ALL/LBL in this study, as absence of TdT expression remained significant in the multivariate analysis that included other known risk factors such as WBC $>100 \times 10^{9} / \mathrm{L}$, CNS involvement, and the ETP immunophenotype, ${ }^{25}$ indicating that TdT expression is an independent risk factor.

Additional risk factors in T-ALL/LBL, including mutation and aberrant expression of $T L X 3,{ }^{26} B A A L C$ and $E R G,^{27}$ and $W T 1,{ }^{28,29}$ have been preferentially observed in cases with an ETP immunophenotype. These genes regulate development of hematopoietic stem cells and are implicated in adverse prognosis of both acute myeloid leukemia (AML) and ALL. ${ }^{30-32}$ It is possible that high expression of ERG, BAALC, or WT1 signifies stem cell-like properties that protect these tumors against chemotherapy. In fact, T-ALL/ LBL with an ETP immunophenotype has a genetic profile more akin to normal hematopoietic and myeloid leukemic stem cells ${ }^{33}$ and may carry FLT3-ITD mutation, a feature typically associated with AML. ${ }^{34}$ TdT is normally expressed in committed T-lymphocytic progenitors. ${ }^{35}$ TdT-negative T-ALL/LBL may be derived from an early stage of $\mathrm{T}$ precursors simply lacking TdT expression or from a later stage of precursors with a perturbed T-cell differentiation. For the TdT-negative T-ALL/LBL without the ETP profile, it is possible that the tumor cells may acquired stem cell properties.

From a practical point of view, the use of TdT as a prognostic marker in patients with T-ALL/LBL has two advantages. First, TdT is widely tested during the initial diagnostic workup of T-ALL/LBL. Second, TdT is an independent risk factor. These features make TdT readily applicable in the clinical setting. T-ALL/LBL is a rare disease and TdTnegative cases represent only a small subset ( $\sim 12 \%)$. A multicenter study may be worthwhile to further confirm the prognostic value of $\mathrm{TdT}$ expression in risk stratification of T-ALL/LBL patients. Our study suggests that patients with TdT-negative T-ALL/LBL belong to a high risk group who may benefit from allogeneic stem cell transplant at the first complete remission.

\section{Acknowledgements}

We thank Dr Robert McKenna for his invaluable critique.

\section{Disclosure/conflict of interest}

The authors declare no conflict of interest.

\section{References}

1 Pui CH, Carroll WL, Meshinchi S, et al. Biology, risk stratification, and therapy of pediatric acute leukemias: an update. J Clin Oncol 2011;29:551-565.

2 Huguet F, Leguay T, Raffoux E, et al. Pediatric-inspired therapy in adults with Philadelphia chromosomenegative acute lymphoblastic leukemia: the GRAALL2003 study. J Clin Oncol 2009;27:911-918.

3 Kantarjian H, Thomas D, O’Brien S, et al. Long-term follow-up results of hyperfractionated cyclophosphamide, vincristine, doxorubicin, and dexamethasone (Hyper-CVAD), a dose-intensive regimen, in adult acute lymphocytic leukemia. Cancer 2004;101: 2788-2801.

4 Marks DI, Paietta EM, Moorman AV, et al. T-cell acute lymphoblastic leukemia in adults: clinical features, immunophenotype, cytogenetics, and outcome from the large randomized prospective trial (UKALL XII/ ECOG 2993). Blood 2009;114:5136-5145.

5 Thomas DA, O'Brien S, Cortes J, et al. Outcome with the hyper-CVAD regimens in lymphoblastic lymphoma. Blood 2004;104:1624-1630.

6 Burkhardt B, Reiter A, Landmann E, et al. Poor outcome for children and adolescents with progressive disease or relapse of lymphoblastic lymphoma: 
a report from the Berlin-Frankfurt-Muenster group. J Clin Oncol 2009;27:3363-3369.

7 Seegmiller AC, Kroft SH, Karandikar NJ, et al. Characterization of immunophenotypic aberrancies in 200 cases of B acute lymphoblastic leukemia. Am J Clin Pathol 2009;132:940-949.

8 Kaleem Z, Crawford E, Pathan MH, et al. Flow cytometric analysis of acute leukemias. Diagnostic utility and critical analysis of data. Arch Pathol Lab Med 2003;127:42-48.

9 Saab GA, Carloss H. Lymphoblastic lymphoma without TdT. N Engl J Med 1980;302:969-970.

10 Shurin SB, Scillian JJ. Absence of terminal transferase may predict failure of remission induction in childhood ALL. Blood 1983;62:81-84.

11 Faber J, Kantarjian H, Roberts MW, et al. Terminal deoxynucleotidyl transferase-negative acute lymphoblastic leukemia. Arch Pathol Lab Med 2000;124:92-97.

12 Brcic I, Labar B, Peric-Balja M, et al. Terminal deoxynucleotidyl transferase negative T-cell lymphoblastic lymphoma in aleukemic patient. Int J Hematol 2008;88:189-191.

13 Roshal M, Fromm JR, Winter S, et al. Immaturity associated antigens are lost during induction for T cell lymphoblastic leukemia: implications for minimal residual disease detection. Cytometry B Clin Cytom 2010;78:139-146.

14 Bruggemann $\mathrm{M}$, Raff $\mathrm{T}$, Flohr $\mathrm{T}$, et al. Clinical significance of minimal residual disease quantification in adult patients with standard-risk acute lymphoblastic leukemia. Blood 2006;107:1116-1123.

15 Raff T, Gokbuget N, Luschen S, et al. Molecular relapse in adult standard-risk ALL patients detected by prospective MRD monitoring during and after maintenance treatment: data from the GMALL 06/99 and 07/03 trials. Blood 2007;109:910-915.

16 Borowitz MJ, Devidas M, Hunger SP, et al. Clinical significance of minimal residual disease in childhood acute lymphoblastic leukemia and its relationship to other prognostic factors: a Children's Oncology Group study. Blood 2008;111:5477-5485.

17 Stow P, Key L, Chen X, et al. Clinical significance of low levels of minimal residual disease at the end of remission induction therapy in childhood acute lymphoblastic leukemia. Blood 2010;115:4657-4663.

18 Inukai T, Kiyokawa N, Campana D, et al. Clinical significance of early T-cell precursor acute lymphoblastic leukaemia: results of the Tokyo Children's Cancer Study Group Study L99-15. Br J Haematol 2012;156:358-365.

19 Coustan-Smith E, Mullighan CG, Onciu M, et al. Early T-cell precursor leukaemia: a subtype of very high-risk acute lymphoblastic leukaemia. Lancet Oncol 2009;10:147-156.

20 Bene MC, Castoldi G, Knapp W, et al. Proposals for the immunological classification of acute leukemias. European Group for the Immunological Characterization of Leukemias (EGIL). Leukemia 1995;9:1783-1786.

21 Drexler HG, Menon M, Minowada J. Incidence of TdT positivity in cases of leukemia and lymphoma. Acta Haematol 1986;75:12-17.
22 Patel JL, Smith LM, Anderson J, et al. The immunophenotype of T-lymphoblastic lymphoma in children and adolescents: a Children's Oncology Group report. Br J Haematol 2012;159:454-461.

23 Thiel E, Kranz BR, Raghavachar A, et al. Prethymic phenotype and genotype of pre-T (CD7 +/ER-)-cell leukemia and its clinical significance within adult acute lymphoblastic leukemia. Blood 1989;73: 1247-1258.

24 Czuczman MS, Dodge RK, Stewart CC, et al. Value of immunophenotype in intensively treated adult acute lymphoblastic leukemia: cancer and leukemia Group B study 8364. Blood 1999;93:3931-3939.

25 Rowe JM, Buck G, Burnett AK, et al. Induction therapy for adults with acute lymphoblastic leukemia: results of more than 1500 patients from the international ALL trial: MRC UKALL XII/ECOG E2993. Blood 2005;106:3760-3767.

26 Baak U, Gokbuget N, Orawa $\mathrm{H}$, et al. Thymic adult T-cell acute lymphoblastic leukemia stratified in standard- and high-risk group by aberrant HOX11L2 expression: experience of the German multicenter ALL study group. Leukemia 2008;22:1154-1160.

27 Baldus CD, Burmeister T, Martus $\mathrm{P}$, et al. High expression of the ETS transcription factor ERG predicts adverse outcome in acute T-lymphoblastic leukemia in adults. J Clin Oncol 2006;24:4714-4720.

28 Chiusa L, Francia di Celle P, Campisi P, et al. Prognostic value of quantitative analysis of WT1 gene transcripts in adult acute lymphoblastic leukemia. Haematologica 2006;91:270-271.

29 Heesch S, Goekbuget N, Stroux A, et al. Prognostic implications of mutations and expression of the Wilms tumor 1 (WT1) gene in adult acute T-lymphoblastic leukemia. Haematologica 2010;95:942-949.

30 Maroulakou IG, Bowe DB. Expression and function of Ets transcription factors in mammalian development: a regulatory network. Oncogene 2000;19:6432-6442.

31 Anderson MK, Hernandez-Hoyos G, Diamond RA, et al. Precise developmental regulation of Ets family transcription factors during specification and commitment to the $\mathrm{T}$ cell lineage. Development 1999;126: 3131-3148.

32 Tanner SM, Austin JL, Leone G, et al. BAALC, the human member of a novel mammalian neuroectoderm gene lineage, is implicated in hematopoiesis and acute leukemia. Proc Natl Acad Sci USA 2001;98: 13901-13906.

33 Zhang J, Ding L, Holmfeldt L, et al. The genetic basis of early T-cell precursor acute lymphoblastic leukaemia. Nature 2012;481:157-163.

34 Hoehn D, Medeiros LJ, Chen SS, et al. CD117 expression is a sensitive but nonspecific predictor of FLT3 mutation in T acute lymphoblastic leukemia and T/myeloid acute leukemia. Am J Clin Pathol 2012;137:213-219.

35 Bogue M, Gilfillan S, Benoist C, et al. Regulation of $\mathrm{N}$-region diversity in antigen receptors through thymocyte differentiation and thymus ontogeny. Proc Natl Acad Sci USA 1992;89:11011-11015. 